\title{
A Rare Case of Acute Symptomatic Seizure, Tetany and Poor Sensorium Secondary to Autosomal Dominant Hypocalcemia and Hypercalciuria
}

\author{
Thirunavukarasu S*, \\ Devi V, Usheva S, \\ Arumugam D, Ramanujam A \\ and Balamurugan $\mathbf{N}$
}

Department of Neurology, Indira Gandhi Government General Hospital and Post Graduate Institute, Puducherry, Puducherry, India

\section{Abstract}

Symptomatic seizures are due to varied etiologies. Genetic disorders causing seizures are well known. Described initially in 1993, Autosomal dominant hypocalcemia with hypercalciuria is a rare genetic disorder, secondary to defective calcium sensing receptor gene (CASR). Two types of mutations can occur in CASR gene which could be activating and inactivating. ADHH occurs due to the activating mutation of the gene. It results in hypocalcemia, hypercalciuria, hypomagnesemia which can manifest as tetany, seizures and worsening sensorium. Here we describe one such case where seizure was the initial presentation followed by tetanic spasms, decreased sensorium and bilateral basal ganglia calcifications in CT brain.

Keywords: Seizures; Tetanic spasms; Decreased sensorium; Basal ganglia calcification; Autosomal dominant hypocalcemia with hypercalciuria

Received: January 11, 2018; Accepted: February 02, 2018; Published: February 19, 2018

\section{Introduction}

Symptomatic seizures contribute to 40 percent of all first time seizures [1]. When two epileptic seizures occur unprovoked by any immediately identifiable cause, it becomes epilepsy. Acute symptomatic seizure, is differentiated from epilepsy when seizure occurs in a close temporal relationship with an insult to central nervous system secondary to metabolic, toxic, structural or genetic causes [1,2]. Symptomatic seizure could be a rare initial presentation of uncommon and rare genetic disorders. Autosomal dominant hypocalcemia with hypercalciuria $(\mathrm{ADHH})$ is a rare genetic disorder due to defective calcium sensing receptor gene (CASR). We encountered one such case with its entire clinical spectrum of seizures, tetany, decreased sensorium and bilateral basal ganglia calcification which we are presenting here.

\section{Case Presentation}

A seventeen year old boy presented to our emergency department with seizures of generalized nature with tongue bite and frothing. He was admitted to the intensive care unit and on examination his vitals were stable. He was in a postictal state with normal fundus examination. He was moving all four limbs; reflexes were

\section{*Corresponding author: \\ Suresh Thirunavukarasu}

Department of Neurology, Indira Gandhi Government General Hospital and Post Graduate Institute, Puducherry, Puducherry, India.

”sureshy2001@yahoo.com

Citation: Thirunavukarasu S, Devi V, Usheva S, Arumugam D, Ramanujam A, et al. (2018) A Rare Case of Acute Symptomatic Seizure, Tetany and Poor Sensorium Secondary to Autosomal Dominant Hypocalcemia and Hypercalciuria. J Rare Disord Diagn Ther. Vol.4 No.1:2

elicitable and plantar were extensor bilaterally. After sending blood samples for biochemical analysis he was loaded with Intravenous (IV) phenytoin at $15 \mathrm{mg} / \mathrm{kg}$ body weight. His seizures were controlled. Subsequently he started developing spasms of generalized nature almost continuously (Figure 1). It was also associated with abnormal posturing. Chvostek's and Trousseau signs were positive. His complete blood count was within normal limits. His blood sugar was $105 \mathrm{mg} / \mathrm{dl}$ and renal parameters were also within normal limits. His ECG revealed prolonged QT interval at $43 \mathrm{~ms}$ and serum calcium was $7 \mathrm{mg} / \mathrm{dl}$. C.T brain plain revealed bilateral basal ganglia hyper densities consistent with calcification (Figure 2). He was immediately loaded with Calcium gluconate 10 mg slow IV over a period of half an hour and was put on calcium supplementation. His tetanic spasms improved but his sensorium did not improve. He was afebrile and his repeat blood counts were normal. Serum ammonia and serum magnesium was checked. While his serum magnesium was very low at $0.6 \mathrm{mg} / \mathrm{dl}$ his serum 


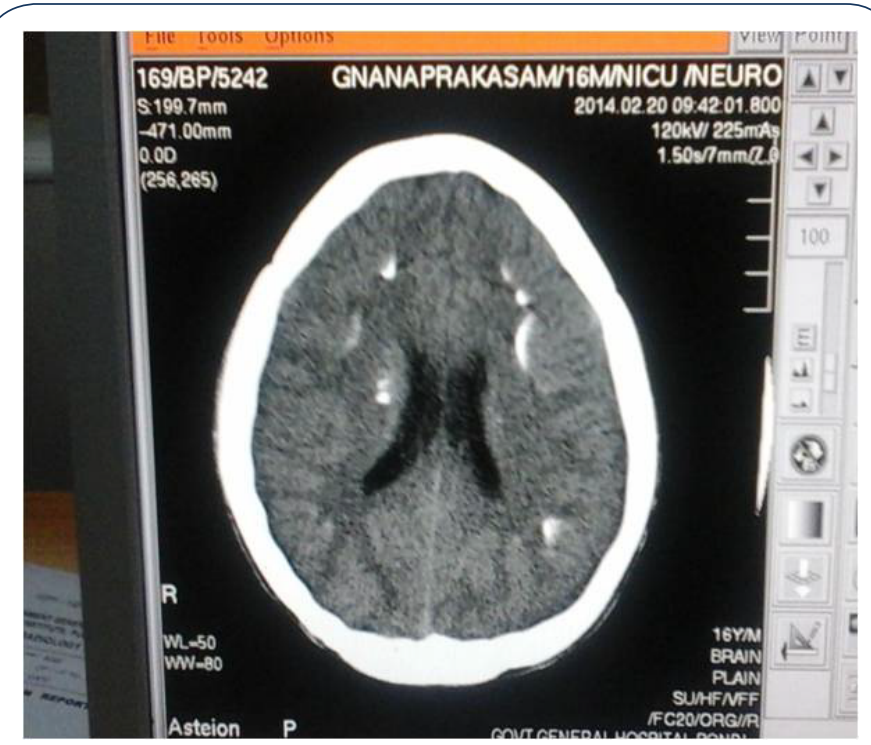

Figure 1 Sending blood samples for biochemical analysis he was loaded with Intravenous (IV) phenytoin at $15 \mathrm{mg} / \mathrm{kg}$ body weight.

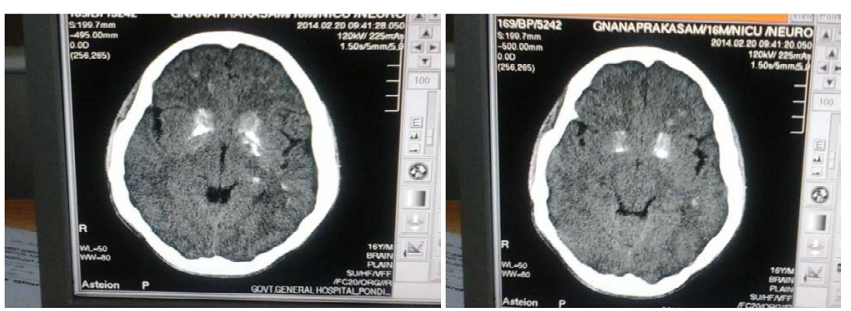

Figure 2 ECG revealed prolonged QT interval at $43 \mathrm{~ms}$ and serum calcium was $7 \mathrm{mg} / \mathrm{dl}$. C.T brain plain revealed bilateral basal ganglia hyper densities consistent with calcification.

ammonia was normal. IV Magnesium sulphate was given $4 \mathrm{gm}$ stat followed by $4 \mathrm{~g}$ over a period of 24 hours as infusion. Within 12 hours his sensorium dramatically improved and he was sitting up next day fully conscious and ambulant. Serum parathormone was low at $8 \mathrm{pg} / \mathrm{ml}$ (ref $10-55 \mathrm{pg} / \mathrm{ml}$ ) and Ultrasound abdomen was normal. 24 hours urinary calcium was high. Arterial blood gas also was done which showed normal anion gap. He was advised diet rich in calcium and magnesium and was advised to continue antiepileptic medications and was discharged from the hospital.

\section{Discussion}

Clinical presentation of the young boy was seizures, tetanic spasms, decreased sensorium and bilateral basal ganglia calcification on C.T brain. His sensorium did not improve even after controlling his seizures and tetanic spasms. The reason for the poor sensorium was decreased magnesium levels which was corrected subsequently. Hypomagnesemia and hypocalcemia can occur together in 3 conditions namely Familial hypomagnesemia with secondary hypocalcemia $(\mathrm{FHH})$, familial hypomagnesemia, hypocalcemia and nephrocalcinosis (FHHN) and autosomal dominant hypocalcemia and hypercalciuria (ADHH) $[3,4]$. Familial hypomagnesemia and hypocalcemia usually occurs in infancy and seizures are the clinical presentation. It is not associated with basal ganglia calcification and hypercalciuria which our patient had. Age of onset in our case was also in second decade which essentially ruled out $\mathrm{FHH}$. FHHN clinically presents with frequent urinary tract infection distal renal tubular acidosis and nephrocalcinosis. In our patient all this was absent which made the diagnosis of FHHN unlikely. ADHH is a clinical entity due to a defective CASR gene [5-7]. CASR gene is a member of the G proteincoupled receptor (GPCR) family. It has a high degree of homology with a variety of other members in this class. This explains why this receptor has been identified in so many different tissues like tubular cells of kidney, stomach, intestines and skin. This diversity of locations explains why the receptor interacts with so many different organ systems in the body to modulate the physiology and pathophysiology [8]. Calcium molecules bind to this protein and along with its signal protein Galpha11 maintains calcium levels. The altered gene becomes more sensitive to calcium. Even low calcium levels send signals via Galpha 11 protein, there by promoting calcium elimination because of the unregulated gene. Effectively there is a lower set point for calcium maintenance by parathormone inhibition therefore enhancing calcium and magnesium excretion. The onset can be from birth to adult hood and the clinical presentation is tetany, seizures and altered sensorium. It is associated with increased urinary excretion of calcium and also with bilateral basal ganglia calcification. Our patient fitted into this diagnosis though we were not able to do the genetic test due to financial constraints. We are reporting this case for its rarity, to explain the interesting association of seizure, hypocalcemia, hypomagnesemia, hypercalciuria and bilateral basal ganglia calcification and for the clinical challenge it provided.

\section{Competing Interests}

There are no competing interests.

\section{Author's Contribution}

Thirunavukarasu $\mathrm{S}$ and Balamurugan $\mathrm{N}$ was the physician incharge of the case, prepared the manuscript, contributed to the diagnosis for the patient, Thirunavukarasu $S$ and Arumugam $D$ was the intensivist involved in the case and helped preparing the draft for the case. Arumugam $D$ and Ramanujam $A$ were involved in daily care of the patient. Devi $V$ and Ramanujam $A$ collected data, did the compilation work and review of literature of the case.

\section{Acknowledgements}

We would like to thank Dr. V. Natarajan, former HOD of Neurology, Madras medical college for reviewing the manuscript and correcting it and also Dr. Raman our director of medical services for encouraging our research work. 


\section{References}

1 Beleza P (2012) Acute symptomatic seizures: a clinically oriented review. Neurologist 18: 109-119.

2 Beghi E, Carpio A, Forsgren L, Hesdorffer DC, Malmgren K (2010) Recommendation for a definition of acute symptomatic seizure. Epilepsia 51: 671-675.

3 Woo SI, Song H, Song KE, Kim DJ, Lee KW, et al. (2006) A case report of familial benign hypocalciuric hypercalcemia: a mutation in the calcium-sensing receptor gene. Yonsei Med J 47: 255-258.

4 Brown EM, Pollak M, Seidman CE, Seidman JG, Chou YH, et al. (1995) Calcium-ion-sensing cell-surface receptors. N Engl J Med 333: 234-240.
5 Thakker RV (2004) Genetics of endocrine and metabolic disorders: parathyroid. Rev Endocr Metab Disord 5: 37-51.

6 Hendy GN, D'Souza-Li L, Yang B, Canaff L, Cole DE, et al. (2000) Mutations of the calcium-sensing receptor (CASR) in familial hypocalciuric hypercalcemia, neonatal severe hyperparathyroidism, and autosomal dominant hypocalcemia. Hum Mutat 16: 28196.

7 Kim MY, Lee JI, Jang HW, Shin HW, Kim SW, et al. (2010) Autosomal Dominant Hypocalcemia Caused by an Activating Mutation of the Calcium-Sensing Receptor Gene: The First Case Report in Korea. J Korean Med Sci 25: 317-320.

8 Beghi E, Carpio A, Forsgren L, Hesdorffer DC, Malmgren K, (2010) Recommendation for a definition of acute symptomatic seizure. Epilepsia 51: 671-675. 